\title{
Effect of multilayer structure parameters on magneto- impedance ratio with low frequency measurements
}

\author{
Vina Oktaria, Candra Tirta Putra, Artono Dwijo Sutomo, Utari, Budi Purnama
}

Physics Department, Universitas Sebelas Maret, Jl. Ir. Sutami 36A, Kentingan, Jebres, Surakarta, 57126, INDONESIA

E-mail: bpurnama@mipa.uns.ac.id

Received 4 October 2019, Revised 8 February 2021, Published 29 March 2020

\begin{abstract}
The magneto-impedance of the NiFe multilayer system is studied dependent on their multilayered structure. The multilayer structures of $[\mathrm{NiFe} / \mathrm{Cu}] 4$ and $[\mathrm{NiFe} / \mathrm{Cu}] 2 / \mathrm{Cu} /[\mathrm{NiFe} / \mathrm{Cu}] 2$ on the meander structure $\mathrm{PCB}$ $\mathrm{Cu}$ substrate in this study were deposited using the electrodeposition method. The frequency was varied in order to determine its effect on the magnetoimpedance ratio. The results of the magneto-impedance characterization measurement showed that the maximum MI ratio in the multilayer $[\mathrm{NiFe} / \mathrm{Cu}] 4$ structure was $6.82 \%$ while in $[\mathrm{NiFe} / \mathrm{Cu}] 2 / \mathrm{Cu} /[\mathrm{NiFe} / \mathrm{Cu}] 2$ was $3.08 \%$ with a frequency of $100 \mathrm{kHz}$. The increase in the MI ratio in the lowfrequency range indicates that the MI ratio depends on the structure of the layer which is affected by the permeability of the magnetic material.
\end{abstract}

Keyword: NiFe, Multilayer, magneto-impedance, low frequency

\section{Introduction}

Magneto-impedance (MI) is defined as a phenomenon of the changes in the impedance of ac currents in magnetic materials as a result of the influence of external magnetic fields (Panina \& Mohri, 1994). The MI effect is very suitable for use in magnetic sensor applications since it has a high sensitivity, even up to the pico-Tesla order (Delooze et al., 2005). In previous studies, by using a multilayer meanderstructure configuration, a large MI ratio that is highly sensitive to external magnetic fields is obtained at relatively low frequencies (Ismail et al., 2016; Prasetyo et al., 2017). The spacer layer of non-magnetic $(\mathrm{Cu}, \mathrm{Ag})$ or semiconductor ( $\mathrm{Ta}, \mathrm{MgO})$ materials are usually used in multilayered systems (Panina \& Mohri, 2000). The presence of this non-magnetic or semiconductor layer produces an induced-biasing field between the magnetic layer so that the higher magnetoimpedance ratio realizes (Panina \& Mohri, 2000; Zhou et al., 2008).

The soft magnetic material with high permeability is suitable for the magnetoimpedance effect realization (Phan \& Xh, 2008; García et al., 2016; Kikuchi et al., 2019; Sayad et al., 2020). The alloy of NiFe such kind Permalloy is a reliable one because it has superior magnetic properties such as high permeability, small 
magnetostrictive coefficient, and low coercivity (Mishra et al., 2017; Chlenova et al., 2017; Vasam \& Srinivas, 2020).

In recent years many studies have been conducted to modify MI ratios with various physical parameter deposition as well as different methods. Meanwhile, this paper reports the dependence of the MI ratio on the addition of a spacer layer $\mathrm{Cu}$ on a multilayer $[\mathrm{NiFe} / \mathrm{Cu}]$. The low frequency of $\mathrm{kHz}$ order is used to evaluate the magnetoimpedance ratio at room temperature following the total impedance sample under various magnetic fields.

\section{Experimental Methods}

In this study, multilayered system $\mathrm{NiFe}$ and $\mathrm{Cu}$ are deposited on a meander-structure PCB $\mathrm{Cu}$ substrate. An electrodeposition procedure is performed for the whole experiment. Electrodeposition is performed using Pt electrodes. Electrolyte solution separately uses for both $\mathrm{Cu}$ and $\mathrm{NiFe}$ deposition. Firstly, the PCB $\mathrm{Cu}$ substrate was cleaned using an ultrasonic cleaner for 15 minutes following the electrodeposition process (Prasetyo et al., 2017). The electrolyte solution is used in the electrodeposition process for the $\mathrm{NiFe}$ layer consists of $\mathrm{NiSO}_{4} .6 \mathrm{H}_{2} \mathrm{O} 0.099 \mathrm{M}, \mathrm{FeSO}_{4} .7 \mathrm{H}_{2} \mathrm{O} 0.012 \mathrm{M}$, $\mathrm{H}_{3} \mathrm{BO}_{3} 0.149 \mathrm{M}, \mathrm{C}_{6} \mathrm{H}_{8} \mathrm{O}_{3} 0.002 \mathrm{M}$. Whereas for the $\mathrm{Cu}$ layer, the electrolyte solution is used was $\mathrm{CuSO}_{4} .5 \mathrm{H}_{2} \mathrm{O} 0.065 \mathrm{M}$ and $\mathrm{C}_{6} \mathrm{H}_{8} \mathrm{O}_{3} 0.002 \mathrm{M}$.

The deposition process for NiFe on PCB Cu substrate is carried out using a current density of $15.5 \mathrm{~mA} / \mathrm{cm}^{2}$. The next step was to coat $\mathrm{Cu}$ with a current density of 8 $\mathrm{mA} / \mathrm{cm}^{2}$. The electrodeposition process was repeated to obtain a multilayer layer (Fig. 1). Figure 1 (a) shows a multilayer illustration of $[\mathrm{NiFe} / \mathrm{Cu}] \mathrm{N}$ with repeated deposition processes up to $\mathrm{N}=4$, later namely sample A. Meanwhile, Figure 1(b) shows the multilayer $[\mathrm{NiFe} / \mathrm{Cu}]_{4}$ when the $\mathrm{Cu}$ spacer layer is inserted so that it changes to $[\mathrm{NiFe} / \mathrm{Cu}]_{2} / \mathrm{Cu} /[\mathrm{NiFe} / \mathrm{Cu}]_{2}$ namely sample $\mathrm{B}$. The electrodeposition process was carried out at room temperature.

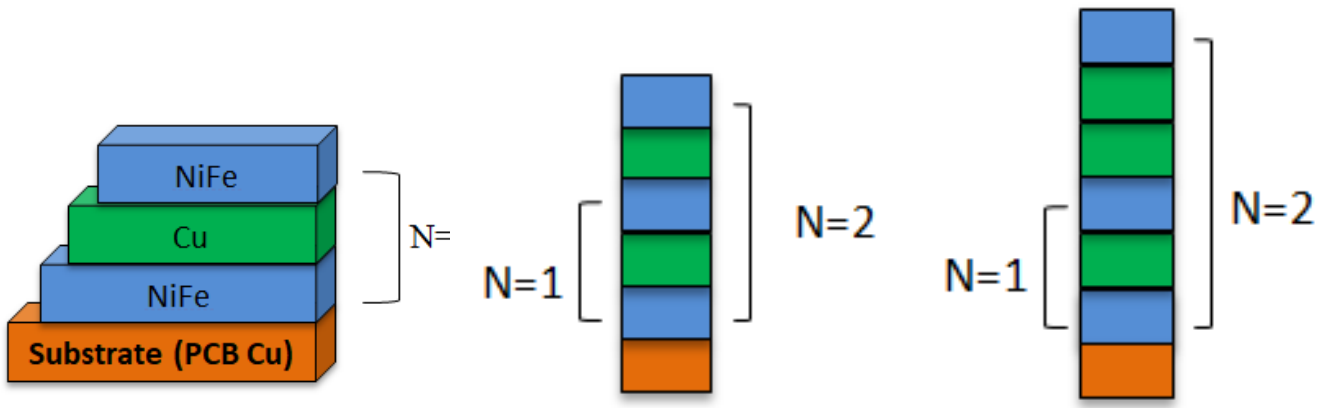

Figure 1. Schematic of multilayer structures (a) $[\mathrm{NiFe} / \mathrm{Cu}]_{\mathrm{N}}$ and (b)

$[\mathrm{NiFe} / \mathrm{Cu}]_{\mathrm{N}} / \mathrm{Cu} /[\mathrm{NiFe} / \mathrm{Cu}]_{\mathrm{N}}$ on PCB $\mathrm{Cu}$ substrate

The obtained multilayer sample is then evaluated for its magneto-impedance characterization. Impedance measurements were carried out using the Instek GW LCR 819 meter to obtain the resistance $(\mathrm{R})$, capacitance (C), and inductance (L) for individual change in the external magnetic field $(H)$. The measured impedance value is the total impedance of the real component $(\mathrm{R})$ and the imaginary component $(\mathrm{X})$. 
Magneto-impedance measurements are carried out by flowing $\mathrm{AC}$ and varying the frequency range of 20-100 kHz. The magneto-impedance measurement scheme is shown in Figure 2. The change in impedance $(Z)$ when given an external magnetic field $(H)$ known as the MI ratio is calculated using Equation 1. The process of measuring magneto-impedance is carried out at room temperature.

$$
M I(\%)=\frac{\Delta \mathrm{Z}}{Z}(\%)=\frac{(Z(H)-Z(\operatorname{Hax}))}{Z(\operatorname{Hax})} \times 100 \%
$$

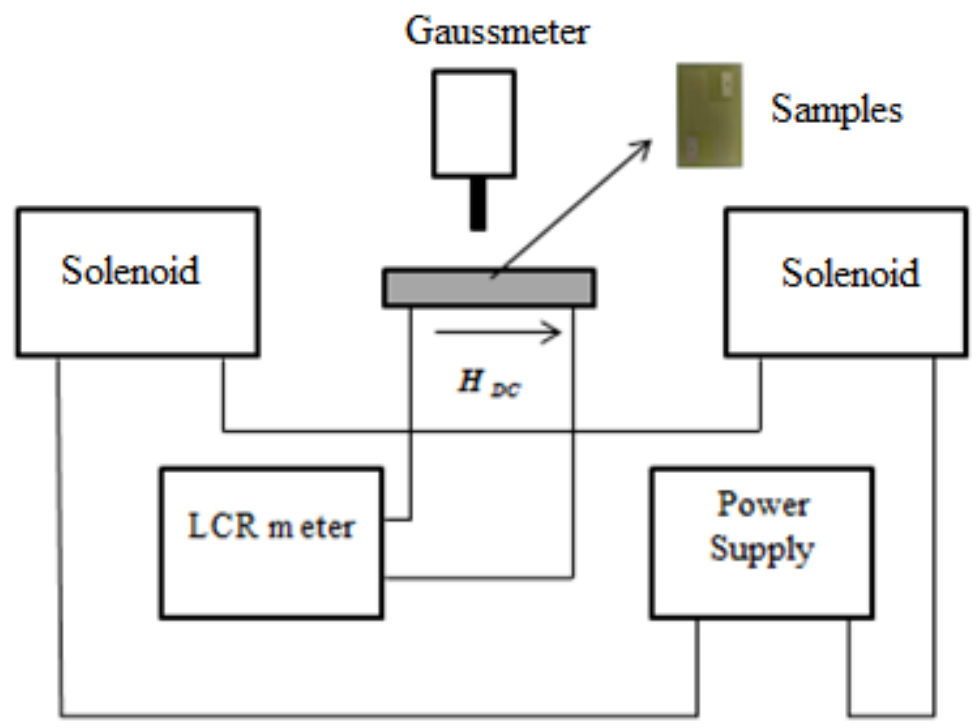

Figure 2. Schematic diagram of the magnetoimpedance measurement

\section{Discussion}
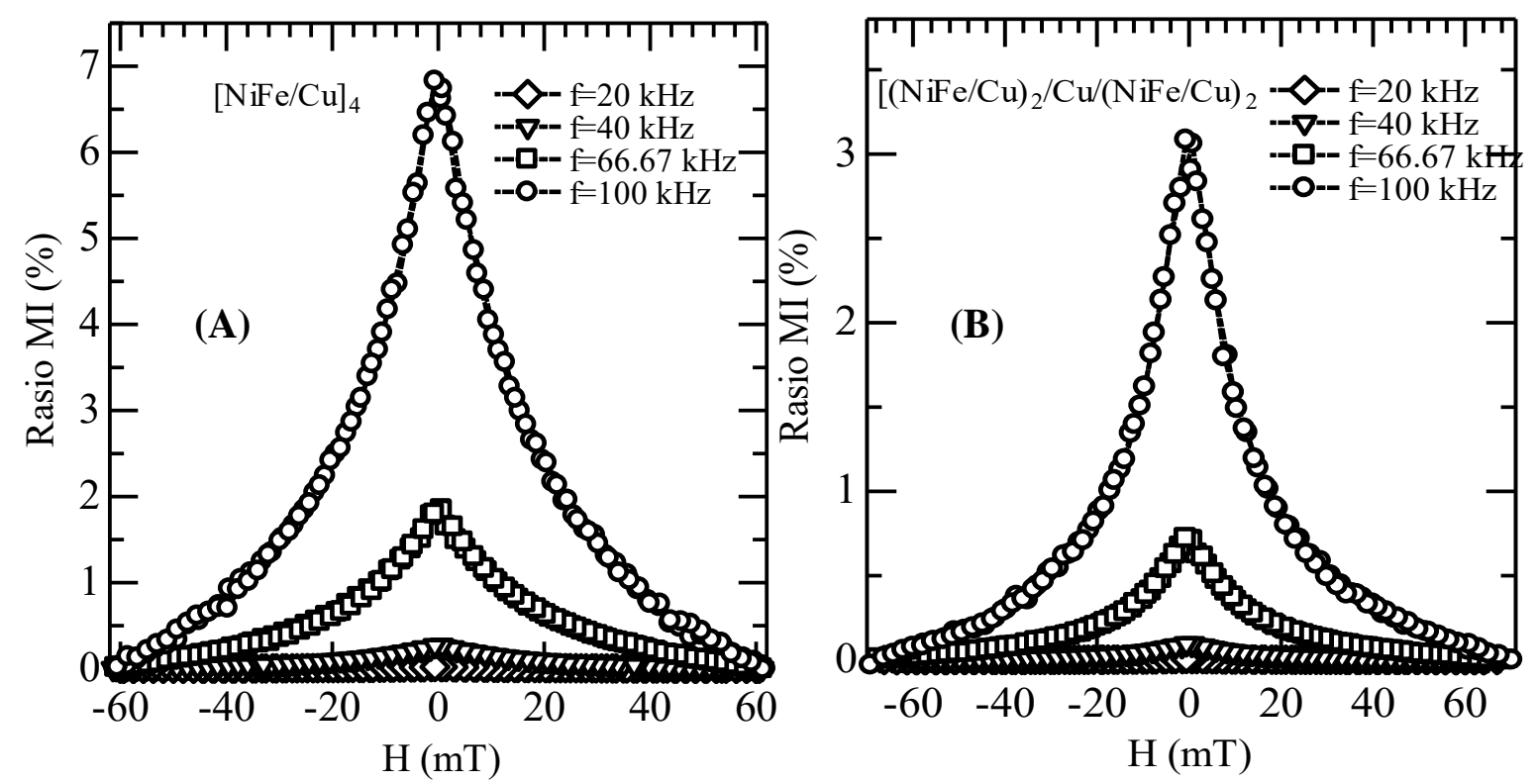

Figure 3. The magnetoimpedance of $\mathrm{MI}-H$ curve for sample A of multilayered $[\mathrm{NiFe} / \mathrm{Cu}]_{4}$ and sample $\mathrm{B}$ of multilayered $[\mathrm{NiFe} / \mathrm{Cu}]_{2} / \mathrm{Cu} /[\mathrm{NiFe} / \mathrm{Cu}]_{2}$

Figures 3(a) and (b) show the curve of the MI ratio $(\Delta \mathrm{Z} / \mathrm{Z})$ as a function of the magnetic field, i.e. sample $A$ of $[\mathrm{NiFe} / \mathrm{Cu}]_{4}$ and sample $\mathrm{B}$ of $[\mathrm{NiFe} / \mathrm{Cu}]_{2} / \mathrm{Cu} /[\mathrm{NiFe} / \mathrm{Cu}]_{2}$ 
multilayered structure, respectively. The MI measurement is performed at room temperature for frequencies in the $20-100 \mathrm{kHz}$ range. It can be seen that the typical MI curve is obtained. For the whole, the variation of the frequency measurement, sample A owing higher MI ratio compares to sample B. It is suggested that two multilayered systems of the $[\mathrm{NiFe} / \mathrm{Cu}]_{2}$ significantly hold back a bias field over to $\mathrm{Cu}$ spacer, which reflects a lower MI ratio.

In the case of sample A, at the lowest frequency $(20 \mathrm{kHz})$, the MI ratio of $0.019 \%$ is obtained, then the MI ratio changes to $0.26 \%, 1.79 \%$, and $6.82 \%$ for the frequency of 40 $\mathrm{kHz}, 66.67 \mathrm{kHz}, 6.82 \%$ respectively. Sample B also shows a similar change in the MI ratio. The MI ratios are obtained $0.006 \%, 0.26 \%, 0.72 \%$, and $3.08 \%$ for frequencies measurement of $20 \mathrm{kHz}, 40 \mathrm{kHz}, 66.67 \mathrm{kHz}$, and $100 \mathrm{kHz}$, respectively. The change in the amount of the MI ratio obtained when the frequency variation is carried out is due to the skin depth value. With an increase in frequency, the skin depth is getting smaller, and the magnitude of the MI ratio which being more dominant influenced by the permeability and thickness of the material (Phan \& Xh, 2008). In addition, an increase in frequency will affect the change in reactance. In the low frequency magnetoimpedance effect measurement, increasing the reactance magnitude will increase of the MI ratio (Feng et al., 2020). This is consistent with the results of previous studies regarding the relationship between MI ratio and frequency (Vasam \& Srinivas, 2020; Zhukov et al., 2020).
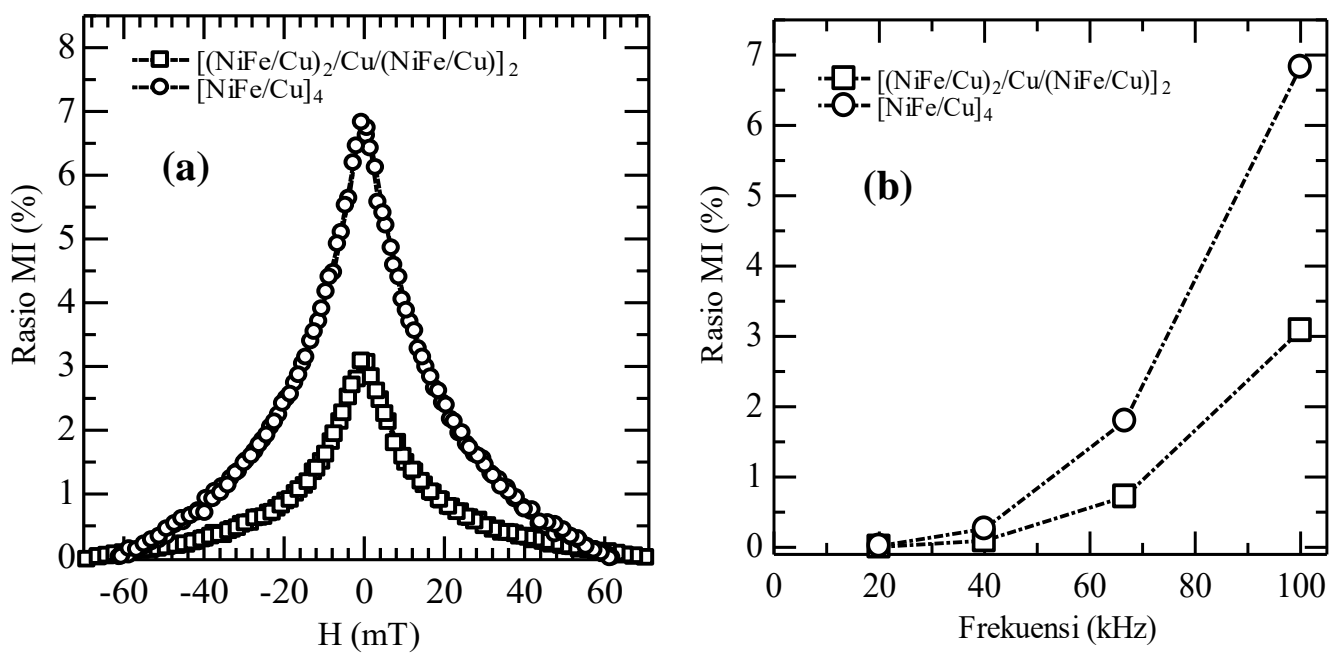

Figure 4. The comparison of the MI ratio in the sample A of the multilayer structure $[\mathrm{NiFe} / \mathrm{Cu}]_{4}$ and the sample $\mathrm{B}$ of $[\mathrm{NiFe} / \mathrm{Cu}]_{2} / \mathrm{Cu} /[\mathrm{NiFe} / \mathrm{Cu}]_{2}$ (a) with a frequency measurement of $100 \mathrm{kHz}$. (b) The MI ratio versus frequencies of 20, 40, 66.67, 100

\section{$\mathrm{kHz}$}

The comparison between the sample A and B can be seen in Figure 4. The results show that the multilayer structure sample A produces a higher MI ratio compared to the structure multilayer sample B as depicted in Fig. 4 (a) i.e. MI ratio sample A of $6.82 \%$ and sample B of $3.08 \%$. Other expressions of the comparison MI ratio as shown in Fig 4(b). This is explained as follows. When the $\mathrm{Cu}$ layer is inserted into the multilayer $[\mathrm{NiFe} / \mathrm{Cu}]_{4}$ structure so that it changes to $[\mathrm{NiFe} / \mathrm{Cu}]_{2} / \mathrm{Cu} /[\mathrm{NiFe} / \mathrm{Cu}]_{2}$, the value of the MI 
ratio will decrease. The bias field between individual multilayered system become smaller because it is blocked by $\mathrm{Cu}$ spacer layer. It is expected the permeability becomes smaller and realize as a smaller magnetoimpedance ratio. Other, the difference in resistance between magnetic and non-magnetic layers also another factor (Panina \& Mohri, 2000). When $\mathrm{Cu}$ is inserted, the non-magnetic layer $(\mathrm{Cu})$ is thicker. Increasing the thickness of the $\mathrm{Cu}$ layer will reduce the resistance of the magnetic layer and the inductance which then decreases. In a multilayer structure, the decrease in inductance will affect the decrease of the MI ratio (Feng et al., 2020).

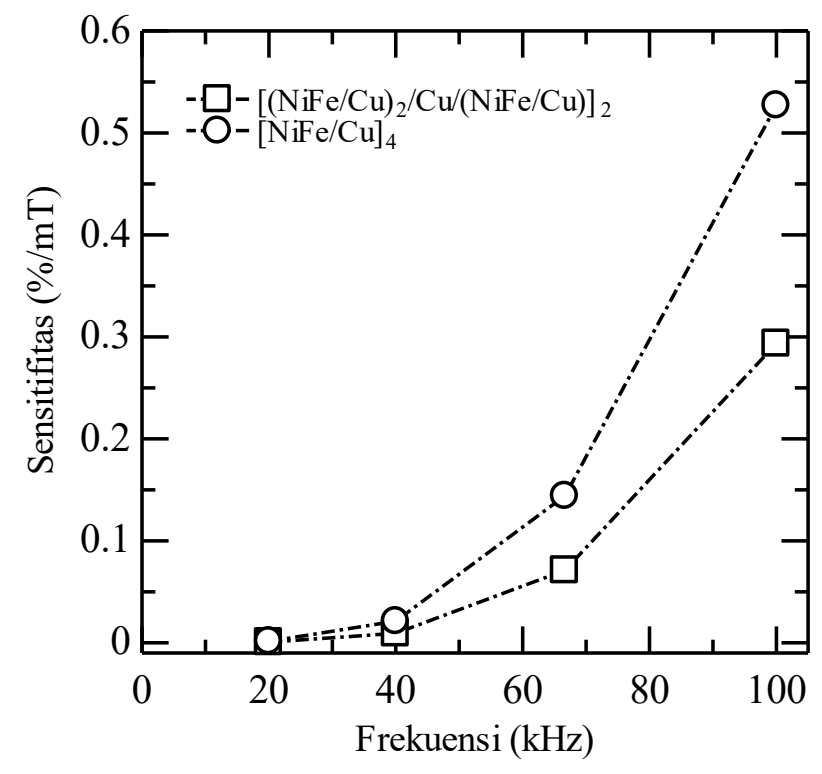

Figure 5. Comparison of the sensitivity to frequency measurements in the sample A of the multilayer $[\mathrm{NiFe} / \mathrm{Cu}]_{4}$ and the sample $\mathrm{B}$ of the $[\mathrm{NiFe} / \mathrm{Cu}]_{2} / \mathrm{Cu} /[\mathrm{NiFe} / \mathrm{Cu}]_{2}$.

The sensitivity of the MI sensor calculates by the equation $\eta=2(\Delta Z / Z)_{\max } / \Delta H$ where $\Delta H$ is the full width at half the maximum height of the MI ratio curve is depicted at Fig 5 for both sample $\mathrm{A}$ of the multilayered $[\mathrm{NiFe} / \mathrm{Cu}]_{4}$ and the sample $\mathrm{B}$ of the multilayered $[\mathrm{NiFe} / \mathrm{Cu}]_{2} / \mathrm{Cu} /[\mathrm{NiFe} / \mathrm{Cu}]_{2}$. The sensitivity value increases with increasing frequency values consistent to the MI ratio. The highest sensitivity of $0.5271 \% / \mathrm{mT}$ is obtained for sample A for frequency measurement of $100 \mathrm{kHz}$. From Figure 5, it can be seen that the sensitivity of the magneto-impedance sensor increases as the magnetoimpedance ratio value (Knobel et al., 2003).

\section{Conclusions}

Magneto-impedance characterization of $\mathrm{NiFe}$ thin films with multilayer structures of $[\mathrm{NiFe} / \mathrm{Cu}]_{4}$ and $[\mathrm{NiFe} / \mathrm{Cu}]_{2} / \mathrm{Cu} /[\mathrm{NiFe}]_{2}$ resulted from electrodeposition. The layer structure greatly affects the increase in the MI ratio. The maximum MI ratio was obtained for the $[\mathrm{NiFe} / \mathrm{Cu}]_{4}$ structure. This indicates that the induce bias field between layer system plays an important role in the magneto impedance MI ratio. The magnetoimpedance sensitivity magnitude is increase consistent with an increase in the magnetoimpedance ratio. 


\section{Acknowledgements}

This research was funded by DIPA Universitas Sebelas Maret of The Republic of Indonesia (Penelitian Unggulan Universitas Sebelas Maret Contract No. 452/UN27.21/PN/2020).

\section{References}

Chlenova, A. A. Moiseev, M. S. Derevyanko, A. V. Semirov, V. N. Lepalovsky, and G. V. Kurlyandskaya. (2017). "Permalloy-Based Thin Film Structures: Magnetic Properties and the Giant Magnetoimpedance Effect in the Temperature Range Important for Biomedical Applications," Sensors, vol. 17, no. 8, p. 1900.

Delooze, P. D. J. Mapps, and L. V. Panina, (2005). “AC biased sub nano tesla magnetic field sensor for low frequency applications utilising magneto impedance in multilayer films," INTERMAG Asia 2005. Digests of the IEEE International Magnetics Conference.

Feng, Z. S. Zhi, X. Sun, L. Yan, C. Liu, and C. Lei. (2020). "Investigation the influence of structure parameters on giant-magnetoimpedance effect measured by noncontact method," Sensor Review, vol. 40, no. 6, pp. 647-656.

García-Arribas, A. E. Fernández, A. Svalov, G. V. Kurlyandskaya, and J. M. Barandiaran. (2016). "Thin-film magneto-impedance structures with very large sensitivity," Journal of Magnetism and Magnetic Materials, vol. 400, pp. 321326.

Ismail, Nuryani, and B. Purnama. (2016). "Influence of sample length to magnetoimpedance effect in electrodeposited $[\mathrm{Cu} / \mathrm{Ni80Fe} 20] 3$ multilayer wires at low frequency.

Kikuchi, H. T. Umezaki, T. Shima, C. Sumida, and S. Oe. (2019). "Impedance Change Ratio and Sensitivity of Micromachined Single-Layer Thin Film MagnetoImpedance Sensor," IEEE Magnetics Letters, vol. 10, pp. 1-5.

Knobel, M. Vázquez, and L. Kraus. (2003). “Giant Magnetoimpedance,” Handbook of Magnetic Materials, pp. 497-563.

Mishra A. C. \& A. K. Jha. (2017). "Variation of magnetoimpedance of electrodeposited $\mathrm{NiFe} / \mathrm{Cu}$ with deposition current density," Indian Journal of Physics, vol. 91, no. 12 , pp. $1535-1540$.

Panina L. V. \& K. Mohri. (1994) "Magneto-impedance effect in amorphous wires," Applied Physics Letters, vol. 65, no. 9, pp. 1189-1191.

Panina, L. \& K. Mohri. (2000). "Magneto-impedance in multilayer films," Sensors and Actuators A: Physical, vol. 81, no. 1-3, pp. 71-77.

Phan M.-H. \& H.-X. (2008). Peng, "Giant magnetoimpedance materials: Fundamentals and applications," Progress in Materials Science, vol. 53, no. 2, pp. 323-420.

Prastyo, W. E. F. Maulana, N. Nuryani, and B. Purnama. (2017). "Magneto-impedance in Multilayered $[\mathrm{Ni} 80 \mathrm{Fe} 20 / \mathrm{Cu}] 4$ with modification of the line-length pattern on Cu printed circuit board," Journal of Physics: Conference Series, vol. 909, p. 012030 .

Sayad, A. E. Skafidas, and P. Kwan. (2020). "Magneto-Impedance Biosensor 
Sensitivity: Effect and Enhancement," Sensors, vol. 20, no. 18, p. 5213.

Vasam S. \& V. Srinivas. (2020). "Microstructure and magnetoimpedance studies of NiFe films electrodeposited on ITO substrate: Experiments and simulations," Journal of Magnetism and Magnetic Materials, vol. 514, p. 167154.

Vasam S. \& V. Srinivas. (2020). "Microstructure and magnetoimpedance studies of $\mathrm{NiFe}$ films electrodeposited on ITO substrate: Experiments and simulations," Journal of Magnetism and Magnetic Materials, vol. 514, p. 167154.

Zhou, Z. Y. Zhou, and Y. Cao. (2008). "The investigation of giant magnetoimpedance effect in meander $\mathrm{NiFe} / \mathrm{Cu} / \mathrm{NiFe}$ film," Journal of Magnetism and Magnetic Materials, vol. 320, no. 20, pp. e967-e970.

Zhukov, A. M. Ipatov, P. Corte-León, L. G.- Legarreta, M. Churyukanova, J. M. Blanco, J. Gonzalez, S. Taskaev, B. Hernando, and V. Zhukova. (2020). "Giant magnetoimpedance in rapidly quenched materials," Journal of Alloys and Compounds, vol. 814, p. 152225. 